\title{
A prospective, single-arm, open-label study to determine the safety and effectiveness of a fixed-dose combination of camylofin and mefenamic acid in Indian women with primary dysmenorrhea
}

\author{
Pragya Pandey ${ }^{1 *}$, Ayushi Asava², K. Hemalatha Nagaraj³ , Sudhanshu Kumar Rath ${ }^{4}$, \\ Vijaya Lakshmi Kodati ${ }^{5}$
}

\author{
${ }^{1}$ Department of Gynecology, Oriana Hospital, Ravindrapuri, Varanasi, Uttar Pradesh, India \\ ${ }^{2}$ Department of Gynecology Alliance Munot Hospital, New Timber Market, Shankashet Road, Bhavani Peth, Pune, \\ Maharashtra, India \\ ${ }^{3}$ Udbhava Hospital, Ittamadu, Banshankari $3^{\text {rd }}$ stage, Banshankari, Bengaluru, Karnataka, India \\ ${ }^{4}$ Kalinga Institutes of Medical Sciences, Campus No 5, KIIT University Road, Bhubaneswar, Odisha, India \\ ${ }^{5}$ Vasavi Medical and Research Center, Lakdikapul, Khairatabad, Hyderabad, Telangana, India
}

Received: 07 August 2021

Accepted: 23 August 2021

\section{*Correspondence: \\ Dr. Pragya Pandey, \\ E-mail: orianacrvns@gmail.com}

Copyright: () the author(s), publisher and licensee Medip Academy. This is an open-access article distributed under the terms of the Creative Commons Attribution Non-Commercial License, which permits unrestricted non-commercial use, distribution, and reproduction in any medium, provided the original work is properly cited.

\begin{abstract}
Background: Treatment of dysmenorrhea is aimed at providing symptomatic relief from associated pain. A prospective, single-arm, open-label, multicenter study was conducted at 5 sites across India to assess the safety, effectiveness and tolerability of a fixed-dose combination (FDC) of camylofin $50 \mathrm{mg}$ and mefenamic acid $250 \mathrm{mg}$ in women with primary dysmenorrhea.

Methods: Women were prescribed a 3/5-day course of the FDC orally thrice daily. The primary endpoint was to assess the safety of the FDC as analyzed by incidence of adverse events (AEs), and the main secondary endpoint was to evaluate effectiveness by change in mean intensity of pain as assessed by visual analog scale (VAS) scoring from baseline to day $3 / 5$.

Results: Out of 274 enrolled women, pain associated with menses was reported by 271 (98.9\%) women at baseline. In all, $28(10.2 \%)$ women reported treatment-emergent AEs. The most common AEs were back pain, headache, vomiting, and upper abdominal pain, which were of mild intensity and resolved at the end of treatment (EoT). None of the women discontinued the study due to AEs. No serious AEs or deaths were reported in the study. The mean (standard deviation [SD]) pain intensity on VAS scale was $72.6(16.28)$ at baseline and $3.3(7.11)$ at EoT. A statistically significant reduction of 69.9 (18.60) from baseline in mean pain intensity was observed after treatment $(\mathrm{p}<0.0001)$.

Conclusions: An FDC of camyolfin and mefenamic acid had a good safety and tolerability profile and could effectively relieve pain in Indian women with primary dysmenorrhea.
\end{abstract}

Keywords: Camylofin, Mefenamic acid, Primary dysmenorrhea, VAS

\section{INTRODUCTION}

Primary dysmenorrhea is a recurrent, spasmodic pain occurring during menstrual cycle without identifiable pelvic pathology, which generally starts soon after menarche and gradually decreases with age while secondary dysmenorrhea is associated with an underlying gynecological disorder. ${ }^{1,2}$ The prevalence of dysmenorrhea is reported to be between $1.7 \%$ and $97 \%$. $^{3}$ In developing countries, the prevalence of dysmenorrhea was between $25 \%$ and $50 \%$ among adult women and about $70 \%$ among adolescents. ${ }^{4}$ Different studies in India have reported that $50 \%$ to $87.8 \%$ of women experience pain 
during menstruation, thereby highlighting the need for medical attention and management. ${ }^{5-7}$

Symptomatic relief and inhibiting the underlying processes that cause symptoms are the aims of treating dysmenorrhea. Non-steroidal anti-inflammatory drugs (NSAIDs) form the first-line treatment for pain relief and improved daily activity. ${ }^{8}$ Mefenamic acid is a conventional and non-selective NSAID. ${ }^{9}$ It decreases the production of prostaglandins by the non-selective inhibition of cyclooxygenase (COX) enzymes. ${ }^{10}$ Studies have confirmed that mefenamic acid reduces pain due to its analgesic activity and also decreases the tone and frequency of uterine contractions. ${ }^{11,12}$ Several studies have reported that mefenamic acid is equivalent to ibuprofen, ketoprofen, piroxicam, and meloxicam in relieving pain. ${ }^{13-}$ ${ }^{16}$ Mefenamic acid was also found to be superior to the combination of dextropropoxyphene and paracetamol in reducing dysmenorrheal pain. ${ }^{17}$ Safety profile of mefenamic acid is similar to that of other NSAIDs, with epigastric and abdominal pain, nausea and anorexia, headache, fatigue reported as frequent adverse reactions. ${ }^{10}$

Spasmodic cramps are the primary symptom of dysmenorrhea. Antispasmodic agents relieve smooth muscle spasms and thereby alleviate pain. Camylofin dihydrochloride has been used as an antispasmodic agent that exerts a dual antispasmodic action: a direct spasmolytic action (musculotropic) on smooth muscles and a mild atropine-like anticholinergic (neurotropic) action, thereby making it a potent antispasmodic agent. Dryness of mouth, dilatation of pupils, and palpitations are common AEs associated with camylofin. ${ }^{17}$

Camylofin dihydrochloride exerts a musculotropic, antispasmodic action with fewer anticholinergic adverse effects. ${ }^{19}$ However, there are no clinical studies published with camylofin dihydrochloride in primary dysmenorrhea. Hence, the present study was designed to assess the effect of camylofin dihydrochloride in primary dysmenorrhea. A combination of antispasmodics and analgesics may provide an additive or synergistic effect during dysmenorrhea. Thus, a combination of camylofin and mefenamic acid may provide better symptomatic relief via inhibition of smooth muscle spasms of and alleviating pain by inhibiting the release of prostaglandins. Nevertheless, there is paucity of real-world data on the safety and effectiveness of camylofin and mefenamic acid combination in treatment of pain associated with primary dysmenorrhea among Indian women. Thus, the present study assessed the safety and effectiveness of a fixed-dose combination (FDC) of camylofin $50 \mathrm{mg}$ and mefenamic acid $250 \mathrm{mg}$ in Indian women with primary dysmenorrhea.

\section{Study objectives}

The primary objective was to assess the safety of the FDC. Secondary objectives were to determine the tolerability of the FDC and its effect on pain intensity as assessed using the 100-mm VAS, frequency of daily pain episodes over a 3-day or 5-day treatment course, meaningful pain relief from baseline to end-of-treatment (EOT), and physicians' global assessment (PGA) based on effectiveness and tolerability at EOT.

\section{METHODS}

This study was a phase IV, prospective, single-arm, openlabel, multicenter study (CTRI/2019/01/017335) conducted at five sites across India over a period of 4 months from May 2019 to August 2019. The study was conducted in compliance with the Principles of the Declaration of Helsinki, International Council for Harmonization-Good Clinical Practice (ICH-GCP) guidelines, and Indian Regulatory Guidelines (Indian Council of Medical Research [ICMR] and Indian GCP guidelines). Prior IEC approval was taken for all studyrelated documents. Written informed consent was obtained from all participants before enrolment.

Each enrolled woman was prescribed per discretion of the treating gynecologist with a 3-day or a 5-day treatment course with Anafortan-MF ${ }^{\circledR}$ (camylofin $50 \mathrm{mg}$ and mefenamic acid $250 \mathrm{mg}$ ) tablets (Manufactured by Accent Pharma and marketed by Abbott healthcare pvt. Itd. Abbott) orally thrice daily. The enrolled women attended two or three visits, including one baseline visit, and a follow-up visit on day 4 and/or day 6 .

\section{Inclusion criteria}

Women aged $\geq 18$ years with a history of moderate to severe primary dysmenorrhea during previous six menstrual cycles including dysmenorrhea on the $1^{\text {st }}$ or $2^{\text {nd }}$ day of their current menstrual cycle were included in the study. Women with a history of taking Anafortan-MF ${ }^{\circledR}$ or any other prescription-only and or non-prescription analgesics, antispasmodics, antidepressants, or antipsychotic medication within the previous 4 weeks before study enrolment were not included in the study.

\section{Exclusion criteria}

Lactating women, women with organic dysmenorrhea, women using an intrauterine contraceptive device, women with cognitive impairment, women with a h/o alcohol abuse or psychiatric illness that could affect the ability of patient to complete patient diary and other assessments, women with history of hypersensitivity to study drugs/any of study drug ingredients, women who had undergone coronary artery bypass graft surgery, and women with epilepsy or inflammatory bowel disease were excluded.

\section{Assessments}

\section{Safety}

Each AE was evaluated for duration, severity, seriousness, and causal relationship to the investigational drug as per the common terminology criteria for adverse events 
(CTCAE) grade. Incidence of overall AEs and incidence of AEs by severity and frequency including significant changes in laboratory parameter values from baseline to day 4 or day 6 and up to post-treatment AE follow-up were recorded.

\section{Tolerability}

Tolerability was assessed as the proportion of women who discontinued study treatment because of AEs before the day 5 .

\section{Effectiveness}

Effectiveness was assessed as percent change in the mean intensity of pain based on the VAS score from baseline to day 3 or day 5 . Patients were asked to record pain intensity in respective patient diaries as scores from 0 for "no pain" to 100 for "worst imaginable pain". Mean change in the frequency of daily pain episodes from baseline to EOT and proportion of women with meaningful pain relief i.e., $\geq 30 \%$ reduction in pain score from baseline to day 3 or day 5 were also analyzed. A questionnaire adapted from the patient global impression of change scale was used to assess PGA pain scores on a 7-point response scale with scores of 1 (no change) to 7 (a great deal better) at EOT.

\section{Statistical analysis}

Sample size was determined based on available literature for gastrointestinal (GI) safety-related incidence rates with mefenamic acid as these are the most common and frequently reported AEs with NSAIDs. ${ }^{16}$ Because of lack of evidence of safety for camylofin dihydrochloride, it was assumed that camylofin dihydrochloride has a similar safety profile as mefenamic acid. With an expected GIrelated AE incidence rate of $20 \%$, a sample size of 246 was required. Using 95\% confidence intervals (CIs) with an error margin of $5 \%$ and assuming that $10 \%$ patients were lost to follow-up, approximately 274 women were to be enrolled in this study.

The primary variable was analyzed using the safety population. The secondary variables were analyzed using intent-to-treat (ITT) and per-protocol (PP) populations. Continuous variables were reported as mean (standard deviation [SD]) and categorical variables were reported as $\mathrm{n}$ and percentage with $95 \%$ CIs.

\section{RESULTS}

\section{Demographics and baseline characteristics}

A total of 274 women were enrolled in the study, out of which 251 (91.6\%) women successfully completed the study. Twenty-three women (8.4\%) were lost to follow up. The mean (SD) age of the study population was 27.4 (7.84) years, and the mean BMI was $22.9(4.42) \mathrm{kg} / \mathrm{m}^{2}$.
Most women (97.1\%) had regular menstrual periods. Intermenstrual bleeding was reported by $96(35.0 \%)$ women, whereas menorrhagia was reported by $32(11.7 \%)$ women. Menorrhagia was severe in $13(4.7 \%)$ women, moderate in 12 women $(4.4 \%)$, and mild in seven women $(2.6 \%)$. Pain associated with the menses was reported by $271(98.9 \%)$ women at the baseline (Table 1).

Table 1: Demographics, baseline characteristics and menstrual history $(n=274)$.

\begin{tabular}{|c|c|}
\hline Parameters & $\mathbf{N}(\%)$ \\
\hline Age (years), mean (SD) & $27.44(7.84)$ \\
\hline BMI $\left(\mathrm{kg} / \mathrm{m}^{2}\right)$, mean $(\mathrm{SD})$ & $22.85(4.42)$ \\
\hline $\begin{array}{l}\text { Patients having regular menstrual } \\
\text { periods*, n }(\%)\end{array}$ & $266(97.1)$ \\
\hline $\begin{array}{l}\text { Duration of bleeding (days), mean } \\
\text { (SD) }\end{array}$ & $4.26(0.90)$ \\
\hline $\begin{array}{l}\text { Patients having inter-menstrual } \\
\text { bleeding, } \mathrm{n}(\%)\end{array}$ & $96(35.0)$ \\
\hline $\begin{array}{l}\text { Patients having menorrhagia, } n \\
(\%)\end{array}$ & $32(11.7)$ \\
\hline \multicolumn{2}{|l|}{ Severity grade of menorrhagia, n (\%) } \\
\hline Mild & $7(2.55)$ \\
\hline Moderate & $12(4.38)$ \\
\hline Severe & $13(4.74)$ \\
\hline $\begin{array}{l}\text { Patients having pain associated } \\
\text { with menses, } n(\%)\end{array}$ & $271(98.9)$ \\
\hline
\end{tabular}

\section{Safety and tolerability}

In total, $28(10.2 \%)$ women reported treatment-emergent AEs. Out of these, $26(9.5 \%)$ were unrelated and only 2 $(0.7 \%)$ were probably related to the study treatments. All reported AEs were of mild intensity (Table 2). No AE was reported for abnormal laboratory parameter (serum chemistry and hematological) in the study. All reported AEs were resolved. None of the women discontinued the study due to AE.

The most common AEs were back pain (4.7\%); headache (1.8\%), vomiting (1.5\%), abdominal pain upper $(1.1 \%)$, and nausea $(0.7 \%)$. All were of mild intensity and resolved at the end of the treatment (Table 2).

\section{Effectiveness}

A statistically significant reduction $(\mathrm{p}<0.0001)$ in VAS score of 69.9 (18.60) for pain intensity was observed at EOT (3.3 [7.11]) from baseline value of 72.6 [16.28]) after treatment with camylofin and mefenamic acid FDC (Table 3 ). The percentage change in the mean intensity of pain from baseline to EOT was $95.5 \%$.

The mean frequency of daily pain episodes reduced from 4.0 (2.51) episodes at baseline to $1.3(0.64)$ episodes at EOT, thus, yielding a reduction of 1.6 (1.20) episodes (Table 3). 
Most women (251/274 [91.6\%]) reported meaningful pain relief (i.e., $\geq 30 \%$ reduction in pain scores from baseline to EOT. Out of these, $183(66.8 \%)$ had no pain by EOT (Table 3).

With regard to the PGA of pain, a majority of the women $(55.8 \%)$ showed better and a definite improvement in pain that made a real and worthwhile difference at EOT, whereas for $17(6.2 \%)$ women, pain was a great deal better and showed a considerable improvement that made all the difference (Figure 1).

The number and percentage of women in each category on a scale of one (no change) to seven (a great deal better) as assessed by the PGA pain scale (Figure 1).

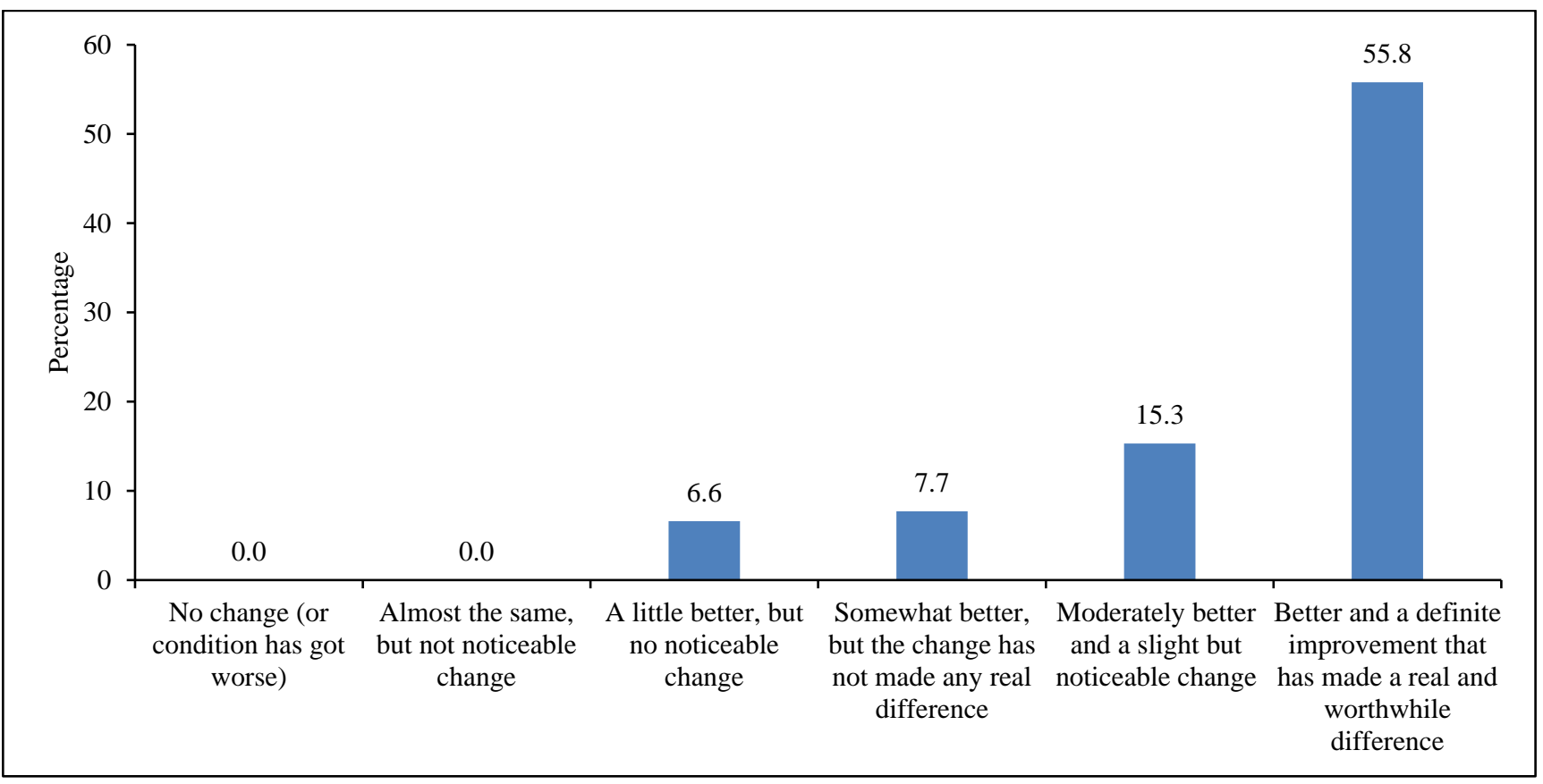

Figure 1: Physicians' global assessment of pain.

Table 2: Summary of treatment-emergent AEs.

\begin{tabular}{|lllll|}
\hline Adverse events & Overall, $(\mathrm{n}=\mathbf{2 7 4})(\%)$ & Outcome & Severity & Relation \\
\hline Any AE & $24(8.8)$ & Resolved & Mild & $\begin{array}{l}\text { Unrelated, }(\mathrm{n}=2) \\
\text { Probable, }(\mathrm{n}=1)\end{array}$ \\
\hline Abdominal pain upper & $3(1.09)$ & Resolved & Mild & Unrelated, $(\mathrm{n}=2)$ \\
\hline Nausea & $2(0.73)$ & Resolved & Mild & Unrelated, $(\mathrm{n}=3)$ \\
\hline Vomiting & $4(1.46)$ & Resolved & Mild & Unrelated, $(\mathrm{n}=1)$ \\
\hline Pain & $1(0.36)$ & Resolved & Mild & Unrelated, $(\mathrm{n}=13)$ \\
\hline Back pain & $13(4.74)$ & Resolved & Mild & Unrelated, $(\mathrm{n}=5)$ \\
\hline Headache & $5(1.82)$ & & & \\
\hline
\end{tabular}

Table 3: Effectiveness of fixed-dose combination of camylofin and mefenamic acid.

\begin{tabular}{|c|c|c|c|c|c|}
\hline \multirow{2}{*}{ Parameters } & \multirow{2}{*}{$\begin{array}{l}\text { Baseline, } \\
(\mathrm{n}=274)\end{array}$} & \multirow{2}{*}{ Visit 2/EOT } & \multicolumn{3}{|c|}{ Change from baseline } \\
\hline & & & Difference & $95 \% \mathrm{CI}$ & $P$ value \\
\hline \multirow{2}{*}{ Pain intensity, mean (SD) } & \multirow{2}{*}{$72.6(16.28)$} & $\mathrm{N}=274$ & & & \\
\hline & & $3.3(7.11)$ & $-69.9(18.6)$ & $-72.2,-67.6$ & $<0.0001$ \\
\hline \multirow{2}{*}{$\begin{array}{l}\text { Frequency of daily pain } \\
\text { episodes, mean (SD) }\end{array}$} & \multirow{2}{*}{$4.0(2.51)$} & $\mathrm{N}=77$ & & & \\
\hline & & $1.3(0.64)$ & $-1.6(1.20)$ & $-1.8,-1.3$ & \\
\hline \multicolumn{2}{|c|}{ Reduction in pain score, $\mathbf{n}(\%)$} & $\mathrm{N}=274$ & & & \\
\hline \multicolumn{2}{|l|}{$\geq 30 \%$ reduction } & $251(91.6)$ & & & \\
\hline \multicolumn{2}{|l|}{$100 \%$ reduction } & $183(66.8)$ & & & \\
\hline
\end{tabular}

CI, confidence interval; EOT, end of treatment; SD, standard deviation. 


\section{DISCUSSION}

Primary dysmenorrhea causes recurrent pain in lower abdominal area that may last for 2-3 days, and the challenge for physicians and gynecologists is to provide complete and quick relief from painful menstruation. However, recent therapies have overcome the challenge to some extent. This prospective, single-arm, open-label, multicenter study was conducted to assess the safety, effectiveness, and tolerability of an FDC of camylofin 50 $\mathrm{mg}$ and mefenamic acid $250 \mathrm{mg}$ in Indian women with primary dysmenorrhea,

The primary variable was to assess the safety (incidence of AEs), where $10.2 \%$ women reported treatment-emergent AEs. The reported AEs were of mild intensity and very few in number, consistent with very few AEs reported in another Indian study. ${ }^{20}$

Effectiveness in reducing mean pain intensity as assessed by VAS scoring and tolerability as assessed by treatment discontinuation were comparable to a randomized comparative clinical study conducted to evaluate the efficacy and tolerability of an oral FDC of camylofin/mefenamic acid versus oral dicyclomine/mefenamic acid given thrice daily for 5 days. ${ }^{21}$ In our study, change in mean pain intensity was $95.5 \%$, which was statistically significant $(\mathrm{p}<0.0001)$ at end of study, while in other study, complete pain relief was experienced by $96 \%$ of patients in the camylofin/mefenamic acid group. The VAS scores reduced by $86 \%$ on day 3 and by $100 \%$ on Day 5 in the camylofin/mefenamic acid group. ${ }^{21}$ Similar results were obtained in the present study. In our study, none of the patients discontinued the study due to AEs and all achieved good tolerance.

In our study, $91.6 \%$ women showed meaningful pain relief at end of treatment where $100 \%$ reduction in pain was reported in $66.8 \%$ patients. In another similar study assessing the clinical efficacy of camylofin in Indian patients with different types of colic pain including dysmenorrhea, good pain relief was observed in all women with dysmenorrhea. ${ }^{20}$

In this study, global assessment of efficacy findings in an earlier study indicated that at least $73 \%$ of the patients receiving the camylofin-mefenamic acid combination rated the treatment as 'very good' to 'excellent' as compared with $54 \%$ of patients receiving the dicyclomine/mefenamic acid combination. ${ }^{21}$ Consistent with these findings, the present study results showed that $55.8 \%$ of patients showed "better and a definite improvement that made a real and worthwhile difference" in pain.

The strength of this study is the well-established efficacy and safety profile of individual components of the FDC, namely, camylofin and mefenamic acid. ${ }^{10,21}$
This study is limited by lower number of sample size and the duration of the study where a long-term study with a greater number of patients might present better results.

\section{CONCLUSION}

In conclusion, in this large, prospective, single-arm, openlabel study involving women with primary dysmenorrhea, a fixed-dose combination of camylofin and mefenamic acid was found to be well tolerated with a good safety profile and significant improvement in pain after 5 days of treatment. Nevertheless, larger, comparative studies with this combination and longer follow up duration are warranted to further strengthen the clinical evidence on safety and efficacy.

\section{ACKNOWLEDGMENTS}

The authors would like to thank Croissance clinical research for providing medical writing support.

Funding: The study was conducted by Accent Pharma, India, as the study sponsor. Abbott Healthcare Private Limited (Abbott) has partially funded Accent Pharma for this study. Anafortan-MF® is marketed in India by Abbott Conflict of interest: None declared

Ethical approval: The study was approved by the Institutional Ethics Committee

\section{REFERENCES}

1. Harel Z. Dysmenorrhea in adolescents and young adults: from pathophysiology to pharmacological treatments and management strategies. Expert Opin Pharmacother. 2008;9(15):2661-72.

2. Dawood MY. Dysmenorrhea. Infertil Reprod Med Clin N Am. 1995;6:363-77.

3. Latthe P, Latthe M, Say L, Gülmezoglu M, Khan KS. WHO systematic review of prevalence of chronic pelvic pain: a neglected reproductive health morbidity. BMC Public Health. 2006;6:177.

4. Harlow SD and Campbell OM. Epidemiology of menstrual disorders in developing countries: a systematic review. BJOG. 2004;111(1):6-16.

5. Agarwal AK, Agarwal A. A study of dysmenorrhea during menstruation in adolescent girls. Indian $\mathrm{J}$ Community Med. 2010;35(1):159-64.

6. Patel V, Tanksale V, Sahasrabhojanee M, Gupte S, Nevrekar P. The burden and determinants of dysmenorrhoea: a population-based survey of 2262 women in Goa, India. BJOG. 2006;113(4):453-63.

7. Omidvar S, Bakouei F, Amiri FN, Begum K. Primary dysmenorrhea and menstrual symptoms in Indian female students: Prevalence, impact and management. Glob J Health Sci. 2016;8(8):135-44.

8. Burnett M, Lemyre M. No. 345-Primary Dysmenorrhea Consensus Guideline. J Obstet Gynaecol Can. 2017;39(7):585-95.

9. Nor Azlin MI, Maryasalwati I, Norzilawati MN, Mahdy ZA, Jamil MA, Zainul Rashid MR. The 
efficacy of etoricoxib vs mefenamic acid in the treatment of primary dysmenorrhoea: a randomized comparative study. J Obstet Gynaecol. 2008;28(4):424-6.

10. Cimolai $\mathrm{N}$. The potential and promise of mefenamic acid. Expert Rev Clin Pharmacol. 2013;6(3):289-305.

11. Pulkkinen MO. Suppression of uterine activity by prostaglandin synthetase inhibitors. Acta Obstet Gynecol Scand. 1979;87:39-43.

12. Tilyard MW, Dovey SM. A comparison of tiaprofenic acid, mefenamic acid and placebo in the treatment of dysmenorrhoea in general practice. Aust N Z J Obstet Gynaecol. 1992;32(2):165-8.

13. Roy S. A double-blind comparison of a propionic acid derivative (ibuprofen) and a fenamate (mefenamic acid) in the treatment of dysmenorrhea. Obstet Gynecol. 1983;61(5):628-32.

14. Hébert JG, Le Morvan P, Bourgouin J. Double-blind comparison of ketoprofen and mefenamic acid in the treatment of primary dysmenorrhea. Clin Ther. 1986;8(3):329-35.

15. Serfaty D. A comparative crossover study of piroxicam vs. mefenamic acid and diclofenac in France. Acta Obstet Gynecol Scand Suppl. 1986;138:19-20.

16. De Mello NR, Baracat EC, Tomaz G, Bedone AJ, Camargos A, Barbosa IC et al. Double-blind study to evaluate efficacy and safety of meloxicam $7.5 \mathrm{mg}$ and $15 \mathrm{mg}$ versus mefenamic acid $1500 \mathrm{mg}$ in the treatment of primary dysmenorrhea. Acta Obstet Gynecol Scand. 2004;83(7):667-73.

17. Anderson AB, Haynes PJ, Fraser IS, Turnbull AC. Study of prostaglandin synthetase inhibitors in primary dysmenorrhoea. Lancet. 1978;1(8060):34548.

18. Warke HS, Chauhan AR, Raut VS, Ingle KM. A Randomised Double-Blind Study-Bombay Hospital J. 2003.

19. Proctor M, Farquhar C. Diagnosis and management of dysmenorrhoea. BMJ. 2006;332(7550):1134-8.

20. Gupta C. Use of Anafortan Intravenous injection for treatment of colicky pain. J Indian Med Assoc. 2000;98(8):479-82.

21. Dhandapani S, Das S, Gangadhar A. A randomised, comparative study to evaluate the efficacy and tolerability of two fixed dose combinations of camylofin and mefenamic acid and dicyclomine and mefenamic acid in the management of primary dysmenorrhea. Indian Practitioner. 2019;70(2):16-20.

Cite this article as: Pandey P, Asava A, Nagaraj KH, Rath SK, Kodati VL. A prospective, single-arm, open-label study to determine the safety and effectiveness of a fixed-dose combination of camylofin and mefenamic acid in Indian women with primary dysmenorrhea. Int J Reprod Contracept Obstet Gynecol 2021;10:3336-41. 